\title{
UMA NOVA ESPÉCIE DE CROSSODACTYLUS DA SERRA DO CIPÓ, MINAS GERAIS, BRASIL (AMPHIBIA, LEPTODACTYLIDAE)
}

ULISSES CARAMASCHI ' IVAN SAZIMA ?

\section{ABSTRACT}

Crossodactylus bokermanni, sp. n., is described from Serra do Cipó, Minas Gerais, Southeastern Brasil. The new species is characterized by the small size $(20-27 \mathrm{~mm})$, slender build, long legs, narrow head, long and acuminate snout, rounded but fairly defined canthus rostralis, and small tympanum. Also, notes on its habits are made and its tadpole is described.

O gênero Crossodactylus Duméril \& Bibron, 1841, contém seis espécies reconhecidas, distribuídas pelo sudeste brasileiro e região de Misiones, Argentina (Lynch, 1971), havendo uma espécie assinalada para o sul do Brasil (Braun \& Braun, 1976, 1980).

Uma população de Crossodactylus encontrada na Serra do Cipó, em Minas Gerais, foi por nós considerada como distinta das demais, sendo aqui descrita como espécie nova. As abreviaturas usadas para identificar os espécimes estudados são: JJ (Coleção Jorge Jim, no Departamento de Zoologia, IBBMA-UNESP, Botucatu, SP) e ZUEC (Coleção do Departamento de Zoologia, Universidade Estadual de Campinas, SP).

\section{Crossodactylus bokermanni, sp. $\mathrm{n}$.}

$$
\text { (Figs. 1-8) }
$$

Diagnose. Espécie de tamanho pequeno $(20-27 \mathrm{~mm})$, porte esguio, pernas longas, cabeça estreita, focinho comprido e acuminado, canto rostral curvo mas definido e tímpano grande.

Holótipo. JJ 6044, fêmea adulta, obtida no $\mathrm{km} 114$ da estrada de Vespasiano a Conceição do Mato Dentro, município de Jaboticatubas, Serra do Cipó, Minas Gerais, Brasil, em 04 de setembro de 1972, por Ivan Sazima e Marlies Sazima.

Parátipos. 18 exemplares adultos, todos colecionados na mesma região que o holótipo, entre os kms 114-126 da estrada de Vespasiano a Conceição do Mato Dentro: JJ 6045-46, 11.xii.1971 (W. C. A. Bokermann e I. Sazima); JJ 6047-49, 06.ii.1972 (W. C. A. Bokermann, I. Sazima e M. Sazima); JJ 6050, 30.iv.1972 (I. Sazima e M. Sazima); JJ 6051, 04.xi.1972 (I. Sazima, M. Sazima e O. C. Oliveira); JJ 6052, $21.1 i .1973$ (I. Sazima, M. Sazima e O. C. Oliveira); JJ 6053, 29.x.1973 (I. Sazima, M. Sazima e O. C. Oliveira); JJ 6054, 12.xii.1973 (W. C. A. Bokermann e I. Sazima); JJ 6055, 14.xii.1973 (W. C. A. Bokermann e I. Sazima); ZUEC 2200, 17.vii.1972 I. Sazima e M. Sazima); ZUEC 2456-58, 05.i.1973 (I. Sazima e M. Sazima); ZUEC 2470, 07.i.1973 (I. Sazima e M. Sazima); ZUEC 3344, 08.ii.1974 (I. Sazima, M. Sazima e O. C. Oliveira); ZUEC 3349, 09.ii.1974 (I. Sazima, M. Sazima e O. C. Oliveira).

Descrição do holótipo. Porte esguio, cabeça pouco mais longa que larga, sua largura $(8,3 \mathrm{~mm})$ contida aproximadamente três vezes no comprimento total (26,6 mm). Focinho, visto de cima (fig. 2), arredondado; visto de perfil (fig. 3), ligeiramente acuminado, com a ponta bem adiante da mandíbula. Olhos grandes, laterais; diâmetro ocular $(3.1 \mathrm{~mm})$ maior que a distância internasal $(2,6 \mathrm{~mm})$ e que a distância narina-olho $(2,3 \mathrm{~mm})$, sendo esta sub-igual à largura da pálpebra superior e ao espaço interorbital. Narinas pequenas, laterais e ligeiramente dirigidas para frente, mais próximas da ponta do focinho 
que dos olhos. Canto rostral curvo, mas definido. Região loreal ligeiramente côncava. Tímpano evidente, aproximadamente circular; diâmetro timpânico $(1,8 \mathrm{~mm})$ cabendo pouco mais que duas vezes no diâmetro ocular; prega dérmica supratimpânica evidente, estendendo-se até próximo à região escapular. Borda do maxilar superior sem espículas córneas. Borda anterior da mandíbula com um lóbulo mediano. Coanas relativamente pequenas, largamente separadas entre si. Dentes vomerianos não perceptíveis. Língua grande, ovóide, pouco entalhada e pouco livre atrás.

Membros anteriores robustos, braços e antebraços aproximadamente da mesma espessura. Mão (fig. 4) com dedos livres, esbeltos, com dilatações terminais e fímbrias pouco desenvolvidas; dedos, em ordem crescente de tamanho, 4-2-1-3; calos subarticulares desenvolvidos, arredondados; calos supranumerários presentes; três espinhos córneos no lado interno do primeiro dedo; tubérculo carpal externo grande, arredondado, aproximadamente duas vezes maior que o tubérculo carpal interno.

Membros posteriores longos, comprimentos da coxa $(12,6 \mathrm{~mm})$ e tíbia $(13,5 \mathrm{~mm})$ juntos pouco menor que o comprimento total. Quando o braço e a coxa são adpressos ao corpo, cotovelo e joelho se sobrepõem ligeiramente. Com as coxas formando ângulo reto com o corpo, e as pernas adpressas às coxas, os calcanhares se sobrepõem ligeiramente. Pé (fig. 5) com artelhos esbel. tos, estes com dilatações terminais pouco desenvolvidas e fímbrias muito evidentes; artelhos, em ordem crescente de tamanho, 1-2-5-3-4; calos subarticulares desenvolvidos, arredondados; calos supranumerários ausentes; membranas interdigitais vestigiais; tubérculos metatarsais desenvolvidos, o externo arredondado e cerca da metade do comprimento do interno, que é alongado; uma fímbria evidente no lado interno do tarso.

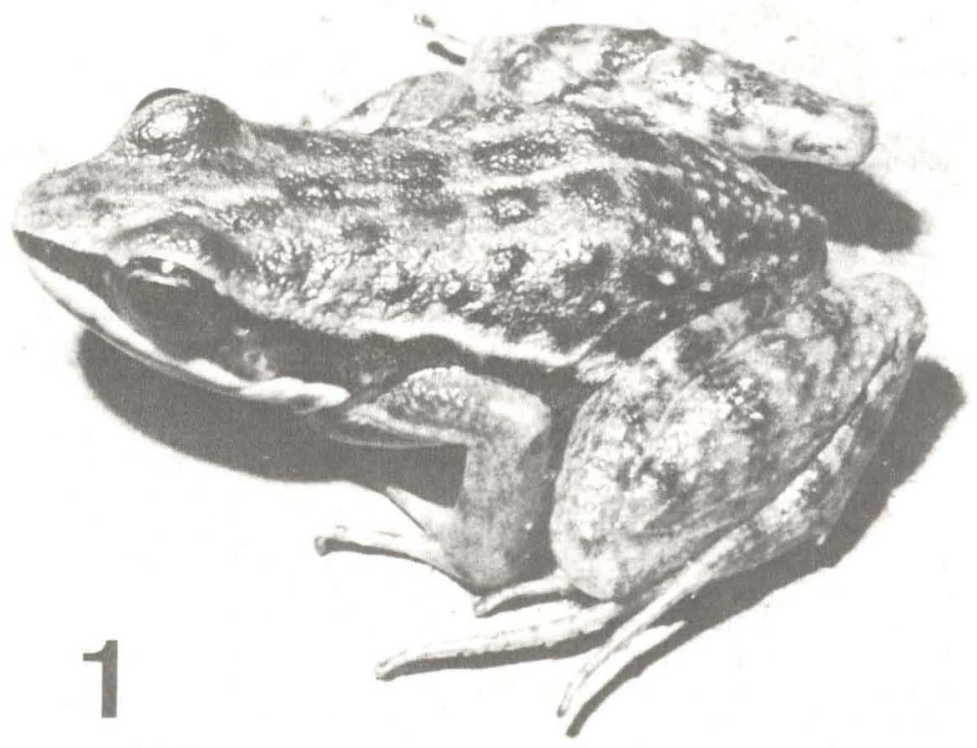

Fig. 1. Crossodactylus bokermanni, sp. n. (ZUEC 2200): aspecto do animal vivo; comprimento total $25,8 \mathrm{~mm}$. 

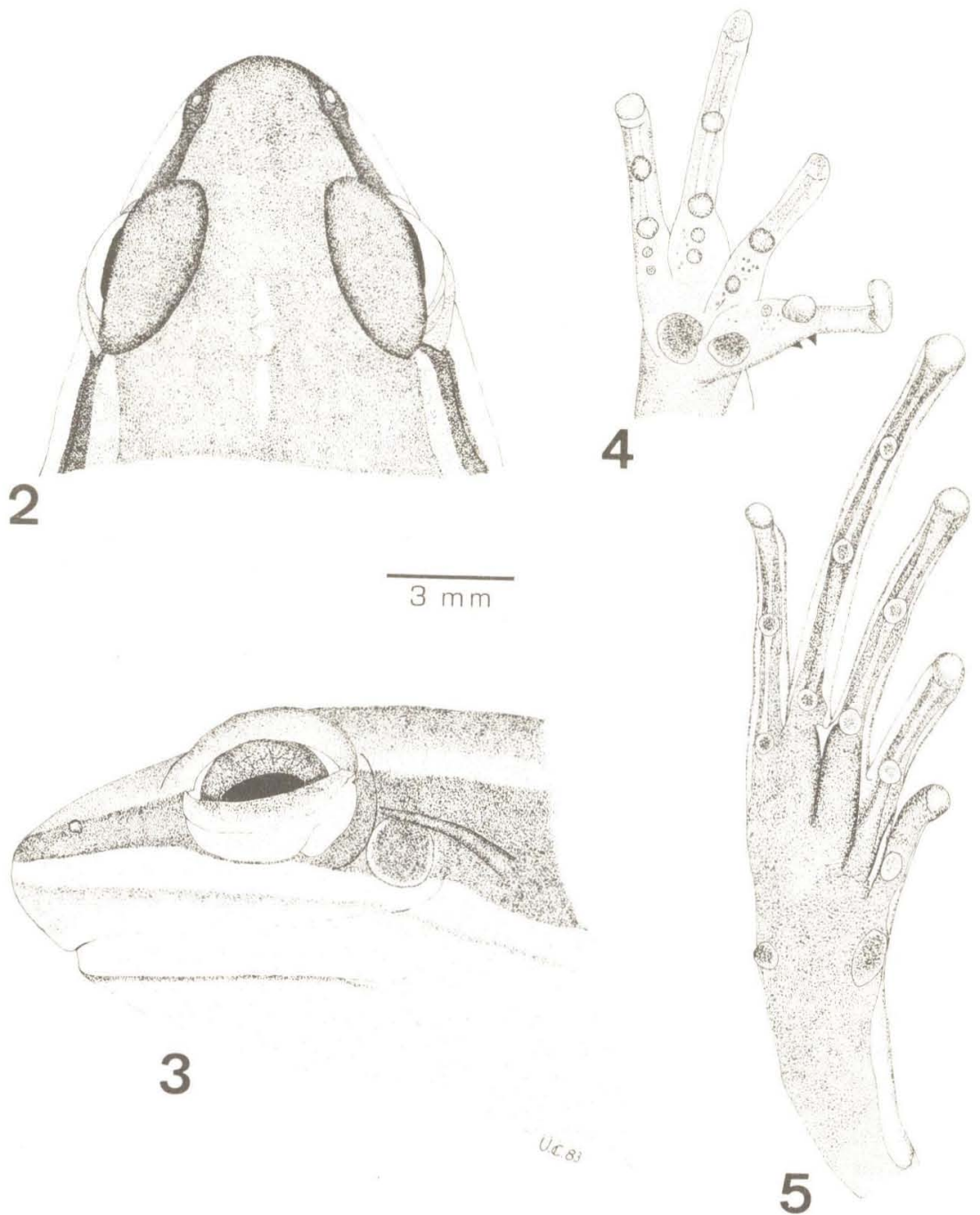

Figs. 2-5. Crossodactylus bokermanni, sp. n., holótipo JJ 6044: 2, cabeça, vista dorsal; 3, cabeça, perfil; 4, mão, vista palmar; 5, pé, vista plantar.

Pele do dorso finamente rugosa, com alguns tubérculos esparsos no terço posterior e na região dorso-lateral. Ventre com pele lisa.

Em preservativo (álcool a $70 \%$ ), colorido de fundo do dorso e regiões laterais, cinza acastanhado. Uma linha média dorsal cinza claro, pouco definida. Uma faixa lateral cinza escuro, indo da ponta do focinho até à região inguinal. Esta faixa é delimitada, na cabeça, pelo canto rostral e por uma faixa brancacenta que vai da ponta do focinho até à comissura bucal; na região lateral do corpo é delimitada por uma faixa cinza claro, que vai da região escapular até à região inguinal, e pela região ventral. Membros ante- 
riores e posteriores cinza acastanhado, com manchas cinza escuro que tendem a formar barras. Região ventral brancacenta, com marmoreado cinza claro. Faces palmar e plantar, cinza.

Variação no colorido. Em vida, o colorido dorsal apresenta-se de cinza amarelado a amarelo oliváceo, por vezes de tons metálicos, com manchas $\mathrm{e}$ barras cinza acastanhado a castanho avermelhado; em alguns exemplares, linha vertebral mais clara. Membros anteriores mais claros. Faixa lateral cinza acastanhado a castanho escuro, limitada inferiormente na cabeça e superiormente no flanco por listra estreita, branco amarelado. Olho amarelo escuro, com vermiculação e faixa horizontal mediana, castanho. Face ventral brancacenta, por vezes com vermiculação cinza claro na região gular. Em preservativo (álcool a 70\%), o colorido geral apresenta-se como o descrito para o holótipo.

Medidas (mínima, máxima e média, em $\mathrm{mm} ; \mathrm{n}=18$ ). Comprimento total 20,3 - 26,6 (23,8); largura da cabeça $6,8-8,6(7,8)$; distância internasal 2,2 - 2,6 (2,4); distância narina-olho $1,8-2,3(2,0)$; diâmetro ocular $2,2-3,1$ $(2,8)$; largura da pálpebra superior $1,7-2,3(2,0)$; distância interorbital 2,0 $2,4(2,2)$; diâmetro timpânico $1,1-1,8(1,5)$; comprimento da coxa $9,7-12,6$ $(11,6)$; comprimento da tíbia 10,6 - 13,5 (12,2).

Girino. Um girino característico (JJ 6056), no estágio 38 (Gosner, 1960), mede $53,2 \mathrm{~mm}$ de comprimento total, dos quais $19,0 \mathrm{~mm}$ são relativos ao corpo. Corpo, visto de lado (fig. 6), aproximadamente triangular, com focinho de contorno arredondado; visto de cima (fig. 7), de forma ovóide. Olhos grandes, dorsais, dirigidos para os lados; diâmetro ocular $(2,3 \mathrm{~mm})$ maior que a distância olho-narina $(1,5 \mathrm{~mm})$ e menor que a distância internasal $(3,3 \mathrm{~mm})$ e que o espaço interorbital $(2,6 \mathrm{~mm})$. Narinas pequenas, dorsolaterais. Nítidas linhas sensitivas nas faces dorsal e laterais do corpo. Espiráculo esquerdo, pequeno, colocado aproximadamente na linha média do corpo. Boca (fig. 8) ventral, pequena, com lábios pouco desenvolvidos, marginados por uma fileira de papilas, exceto na região mediana anterior. Fórmula dentária $2 / 3$, as duas séries interiores de dentículos interrompidas medianamente; bico córneo desenvolvido, com bordas denteadas. Tubo anal dextro, curto e largo. Cauda longa e musculosa; comprimento da cauda $(34,2 \mathrm{~mm})$ pouco menos que duas vezes o comprimento do corpo; altura da cauda $(12,1 \mathrm{~mm})$ pouco maior que a altura do corpo $(10,2 \mathrm{~mm})$. Nadadeiras desenvolvidas, a dorsal pouco mais larga que a ventral; nadadeira dorsal com início no final do corpo. Em preservativo (formalina a 5\%), colorido geral do dorso, acinzentado, sendo nítidas as pontuações brancacentas das linhas sensitivas. Ventre cinza acastanhado, pouco transparente, mas deixando visíveis as espiras intestinais. Musculatura da cauda, castanho; nadadeiras hialinas; manchas castanho escuro esparsas, sem formar desenho definido, mais densas no terço posterior da cauda.

Jovens recém-metamorfoseados medem 16,6 - 17,6 mm $(\overline{\mathrm{x}}=17,2 ; \mathrm{n}=5)$ de comprimento total.

Hábitos. Crossodactylus bokermanni, sp. n., tem sido encontrada em campos rupestres (Joly, 1970; Sazima \& Bokermann, 1977), às margens de riachos permanentes, com fundo areno-rochoso e vegetação marginal herbácea e arbustiva. Machos e fêmeas foram encontrados em diversas épocas, ao longo do ano. É um anuro ágil, de atividade diurna, sendo o seu comportamento semelhante ao das demais espécies do gênero. Os machos vocalizam durante a maior parte do ano; ao ouvido humano, seu chamado de advertência é semelhante ao de outras espécies de Crossodactylus. Girinos de $C$. bokermanni, sp. n., foram encontrados em diversas épocas ao longo do ano. Permanecem sobre o substrato areno-rochoso e parecem ter atividade predominantemente diurna. Sua coloração dorsal, castanho claro com pontos e pequenas manchas castanho escuro, é homocrômica com o substrato. Jovens recém-metamorfoseados medem aproximadamente dois terços do comprimento do animal adulto, o que sugere uma vida aquática longa, talvez em torno de seis meses ou mais. 


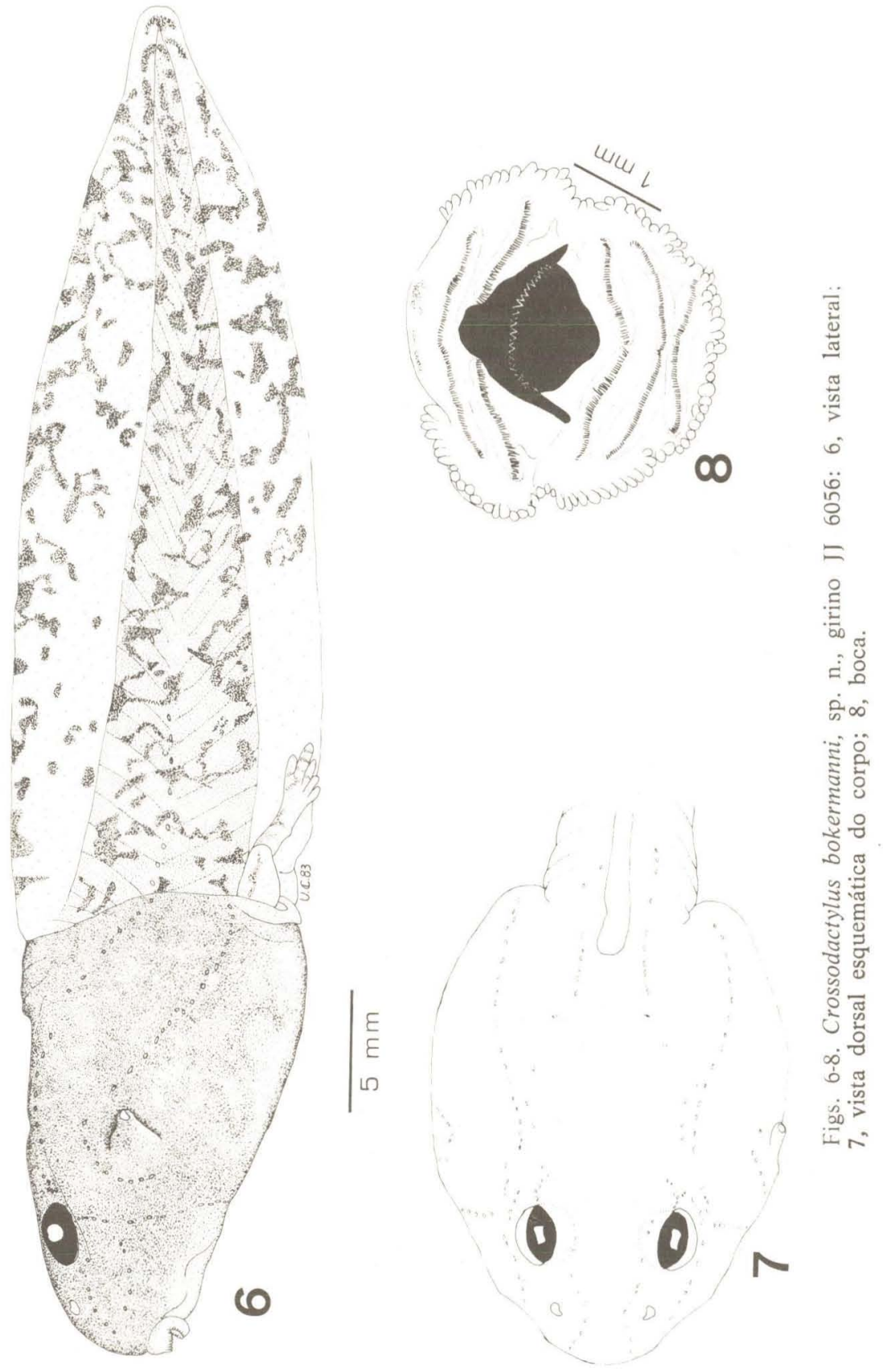


Etimologia. O nome específico é uma homenagem a Werner C. A. Bokermann, em reconhecimento à sua fundamental contribuição ao estudo dos anuros brasileiros.

Discussão. As seis espécies reconhecidas como pertencentes ao gênero Crossodactylus podem ser separadas em três grupamentos distintos. O primeiro contém C. gaudichaudii Duméril \& Bibron, 1841 e C. aeneus L. Mueller, 1924, que se caracterizam pelo focinho acuminado e canto rostral bem marcado. O segundo contém C. trachystomus (Reinhardt \& Luetken, 1862), C. dispar A. Lutz, 1925 e C. grandis B. Lutz, 1951, que se caracterizam pelo focinho curto, de contorno arredondado e canto rostral pouco evidente. $O$ último contém apenas C. schimidti Gallardo, 1961, que se caracteriza pelo focinho muito curto, canto rostral arredondado e grande espaço interorbital.

Crossodactylus bokermanni, sp. n., aproxima-se das espécies componentes do primeiro grupamento pelo seu aspecto geral, apesar de não possuir o canto rostral tão marcado; além disso, a nova espécie distingue-se destas espécies pelo tamanho menor, pernas mais longas, cabeça mais estreita e tímpano menor. Das espécies pertencentes ao segundo grupamento, $C$. bokermanni, sp. n., distingue-se prontamente pelo porte mais esguio, pernas mais longas, cabeça mais estreita e tímpano menor, além do perfil e maior comprimento do focinho. De $C$. schimidti, a nova espécie distingue-se prontamente pelo menor tamanho, porte mais esguio, pernas mais longas e cabeça mais estreita, além do focinho mais comprido, canto rostral mais evidente e menor espaço interorbital.

Nas espécies de Crossodactylus, as características sexuais secundárias são pouco evidentes, à parte de braços pouco mais robustos nos machos. Ambos os sexos apresentam espinhos córneos na base do primeiro dedo, caráter considerado por Miranda-Ribeiro (1926) e Lynch (1971) como restrito aos machos. O número desses espinhos é bastante variável, intra e inter-especificamente, como demonstrou Cochran (1955), o que torna esse caráter de baixo valor diagnóstico. À parte essa restrição, C. bokermanni, sp. n., é espécie que apresenta baixos números de espinhos, fracamente desenvolvidos no primeiro dedo, sendo que 11 exemplares apresentam dois, e 8 exemplares, três espinhos em cada dedo, no lote examinado. Problema semelhante se dá com o caráter presença de espinhos córneos no lábio superior, os quais Gallardo (1961) diz poderem ser interpretados como a persistência da fileira superior, mais externa, dos dentículos córneos do girino. Tal caráter também não fornece evidência de dimorfismo sexual (Cochran, 1955), como também a presença ou ausência de tais espinhos é bastante variável intra e inter-especificamente, indo desde a ausência total até uma fileira completa de espinhos escuros, passando por espinhos pequenos e brancos, ou espinhos escuros esparsos. Em C. bokermanni, sp. n., os espinhos córneos labiais estão ausentes ou, no máximo, existe o esboço de alguns espinhos brancos, nos exemplares examinados.

Com relação aos girinos, das espécies de Crossodactylus são conhecidos apenas os de C. schimidti (Gallardo, 1961; Cei, 1980), C. dispar (Bokermann, 1963) e C. trachystomus (Caramaschi \& Kisteumacher, 1983). Destes, o girino da nova espécie distingue-se pelo formato e proporções gerais do corpo e da cauda, além de detalhes de colorido.

Agradecimentos. Somos gratos a Werner C. A. Bokermann, pelo valioso apoio, discussões, empréstimo de material e auxílio nos trabalhos de campo e na coleta de exemplares. A Marlies Sazima e Otavio C. de Oliveira, pelo auxílio nos trabalhos de campo, nas fotografias e na coleta de exemplares.

\section{REFERENCIAS}

Bokermann, W. C. A., 1963. Girinos de anfíbios brasileiros - 2 (Amphibia, Salientia). Revta bras. Biol. 23(4): 349-353.

Braun, P. C. \& Braun, C. A. S., 1976. Primeira ocorrência do gênero Crossodactylus Duméril \& Bibron, 1841 no Estado do Rio Grande do Sul, registrada através do encontro de Crossodactylus dispar A. Lutz, 1925 
(Anura, Leptodactylidae). Com. Mus. Ciênc. PUCRGS (Zool.), 10/11: 17-24.

Braun, P. C. \& Braun, C. A. S., 1980. Lista prévia dos anfíbios do Estado do Rio Grande do Sul, Brasil. Iheringia (Zool.) 56: 121-146.

Caramaschi, U. \& Kisteumacher, G., 1983. O girino de Crossodactylus trachystomus (Reinhardt \& Luetken) (Amphibia, Anura, Leptodactylidae). Res. X Congr. bras. Zoologia. pp 305-306.

Cei, J. M., 1980. Amphibians of Argentina. Monitore Zool. Ital. (N. S.), monog. 2: $\mathrm{xii}+609$.

Cochran, D. M., 1955. Frogs of Southeastern Brazil. Bull. U. S. natn. Mus., 206: $\mathrm{xvi}+423$.

Gallardo, J. M., 1961. Anfibios anuros de Misiones con la descripcion de una nueva especie de Crossodactylus. Neotropica 7(23): 33-38.

Gosner, K. L., 1960. A simplified table for staging anuran embryos and larvae with notes on identification. Herpetologica 16(3): 183-190.

Joly, A. B., 1970. Conheça a Vegetação Brasileira. Ed. Polígono S.A. - Ed. da USP, São Paulo, xiii + 260 pp., il.

Lynch, J. D., 1971. Evolutionary relationships, osteology and zoogeography of leptodactyloid frogs. Univ. Kansas Mus. nat. Hist., Misc. Publ. n.o 53: $1-238$.

Miranda-Ribeiro, A. de, 1926. Notas para servirem ao estudo dos Gymnobatrachios (Anura) brasileiros. Archos Mus. nac. Rio de Janeiro 27: 1-227, 22 pls.

Sazima, I. \& Bokermann, W. C. A., 1977. Anfíbios da Serra do Cipó, Minas Gerais, Brasil. 3: Observações sobre a biologia de Hyla alvarengai Bok. (Anura, Hylidae). Revta bras. Biol. 37(2): 413-417. 